\title{
Visual complexity attenuates emotional processing in psychopathy: Implications for fear-potentiated startle deficits
}

\author{
Naomi Sadeh • Edelyn Verona
}

Published online: 21 December 2011

(C) Psychonomic Society, Inc. 2011

\begin{abstract}
A long-standing debate is the extent to which psychopathy is characterized by fundamental deficits in attention or emotion. We tested the hypothesis that the interplay of emotional and attentional systems is critical for understanding processing deficits in psychopathy. A group of 63 offenders were assessed using the Psychopathy Checklist: Screening Version. Event-related brain potentials (ERPs) and fearpotentiated startle (FPS) reflexes were collected while participants viewed pictures selected to disentangle an existing confound between perceptual complexity and emotional content in the pictures typically used to study fear deficits in psychopathy. As predicted, picture complexity moderated the emotional processing deficits. Specifically, the affectiveinterpersonal features of psychopathy were associated with greater allocation of attentional resources to processing emotional stimuli at initial perception (visual N1), but only when the picture stimuli were visually complex. Despite this, results for the late positive potential indicated that emotional pictures were less attentionally engaging and held less motivational significance for individuals high in affective-interpersonal traits. This deficient negative emotional processing was observed later in their reduced defensive fear reactivity (FPS) to high-complexity unpleasant pictures. In contrast, the impulsive-antisocial features of psychopathy were associated with decreased sensitivity to picture complexity (visual N1) and were unrelated to emotional processing, as assessed by both ERPs and FPS. These findings are the first to demonstrate that picture complexity moderates FPS deficits, and they implicate the interplay of attention and emotional systems as deficient in psychopathy.
\end{abstract}

N. Sadeh $(\bowtie) \cdot$ E. Verona

University of Illinois at Urbana-Champaign,

603 East Daniel Street,

Champaign, IL 61801, USA

e-mail: naomisadeh@gmail.com
Keywords Psychopathy · Fear-potentiated startle · Visual complexity Emotion $\cdot$ Event-related potentials

There is increasing interest in clarifying the neurobiological vulnerabilities associated with psychopathy, a disorder characterized by a constellation of affective-interpersonal deficits (e.g., duplicity, grandiosity, manipulativeness, and callousness) and impulsive-antisocial behaviors (e.g., thrill-seeking, irresponsibility, and violence; Harpur, Hare, \& Hakstian, 1989). Prominent etiological models of psychopathy differ in the emphasis placed on emotional versus cognitive deficits for the development of the disorder, which has led to disagreement about what neural processes are aberrant in psychopathy (R. J. R. Blair \& Mitchell, 2009; Kiehl, 2006; Newman, 1998). Furthermore, the affectiveinterpersonal and impulsive-antisocial dimensions often evidence different relationships with psychological, biological, and environmental indicators (Benning, Patrick, Hicks, Blonigen, \& Krueger, 2003; Gordon, Baird, \& End, 2004; Harpur et al., 1989; Ross, Benning, Patrick, Thompson, \& Thurston, 2009; Verona, Patrick, \& Joiner, 2001), suggesting that they may index distinct risk factors for the manifestation of psychopathy. The goal of the present study was to test the hypothesis that interactive emotion-cognition deficits manifest differentially across the psychopathy dimensions.

\section{Dual-deficit theory}

Although Cleckley (1941) originally conceptualized psychopathy as a unitary disorder, contemporary psychometric research on the structure of psychopathy supports a multidimensional conceptualization of the construct, in that at least two sets of traits vary dimensionally across individuals 
(e.g., Edens, Marcus, Lilienfeld, \& Poythress, 2006; Harpur et al., 1989). The first dimension describes the affective and interpersonal features of psychopathy, and the second dimension describes an impulsive, irresponsible, and antisocial lifestyle (e.g., Harpur et al., 1989). The affective-interpersonal dimension has been associated with low levels of anxiety and fear, resilience against mood disorders, and intact general intelligence (Benning et al., 2003; Harpur et al., 1989; Ross et al., 2009), whereas the impulsive-antisocial dimension has been associated with high levels of anxiety and distress, a range of comorbid psychopathology (e.g., major depressive disorder, posttraumatic stress disorder, or substance dependence), low general intelligence, and elevated rates of psychosocial adversity (e.g., poverty or childhood abuse) (Benning et al., 2003; Harpur et al., 1989; Reardon, Lang, \& Patrick, 2002; Smith \& Newman, 1990; Verona et al., 2001). These findings have led noted researchers to suggest that the two main psychopathy dimensions represent distinct etiological pathways to the manifestation of antisocial behavior that are each characterized by distinct emotional and cognitive impairments instantiated in separable neurobiological systems (e.g., Fowles \& Dindo, 2009; Patrick \& Bernat, 2009). The present study helps to advance the literature by examining the distinct patterns of cognition-emotion interactions associated with each dimension.

\section{Cognition, emotion, and dimensions of psychopathy}

For decades, theorists have postulated that psychopathy is associated with deficits in the emotional circuitry of the brain that modulates the experience of fear, such as the amygdala and the paralimbic system (e.g., Hare, 1965; Lykken, 1957). This theory is supported by a substantial body of research linking psychopathy to deficits in aversive conditioning (e.g., Flor, Birbaumer, Hermann, Ziegler, \& Patrick, 2002; Hare, 1965) and passive avoidance learning (e.g., Lykken, 1957; Newman \& Kosson, 1986). Laboratory research has found that the deficient emotionality described by the low-fear model is specific to the affective-interpersonal dimension (e.g., Benning, Patrick, \& Iacono, 2005; Gordon et al., 2004; Patrick, Bradley, \& Lang, 1993). For example, research has found that fear-potentiated startle reflex (FPS), a measure of defensive reactivity of motivational systems to threatening stimuli (Bradley, Cuthbert, \& Lang, 1989; Grillon \& Baas, 2003; Kim \& Davis, 1993), is inversely related to the affective-interpersonal psychopathy symptoms but remains unchanged as a function of scores on the impulsive-antisocial dimension (Benning et al., 2005; Patrick et al., 1993; Vaidyanathan, Hall, Patrick, \& Bernat, 2011). Furthermore, functional magnetic resonance imaging (fMRI) research has indicated that the affective-interpersonal dimension is related to decreased activation in the amygdala during the processing of emotional stimuli, whereas the impulsiveantisocial dimension is associated with increased neural activation in brain regions related to emotional processing and reward anticipation, including the amygdala and nucleus accumbens (Buckholtz et al., 2010; Gordon et al., 2004). In combination, these studies suggest that the affectiveinterpersonal dimension is negatively related to emotional reactivity, particularly deficient defensive activation of motivational systems that are important for responding to threatening stimuli. In contrast, the impulsive-antisocial dimension appears to be related to enhanced emotional processing and reactivity to stress (Lorber, 2004), though not necessarily to an increased fear response to threatening stimuli (using FPS).

Emotion-based etiological models cannot fully account for the information-processing deficits observed in studies of psychopathy. For instance, psychopathic individuals perform abnormally on tasks that involve processing neutral stimuli, such as color-word Stroop, flanker, and dualattention tasks (Hiatt, Schmitt, \& Newman, 2004; Jutai \& Hare, 1983; Zeier, Maxwell, \& Newman, 2009). On the basis of evidence that psychopathic individuals screen out distractors when attention is taxed (e.g., Hiatt et al., 2004; Jutai \& Hare, 1983) and display appropriate emotional responses when attention is focused on emotional stimuli (Baskin-Sommers, Curtin, \& Newman, 2011; Glass \& Newman, 2006; Newman, Curtin, Bertsch, \& BaskinSommers, 2010), the development of affective and interpersonal deficits in psychopathy has also been attributed to deficits in selective attention, rather than deficiencies in emotional reactivity per se. In particular, the attention deficits in psychopathy appear to reflect an early selection bias or bottleneck that limits processing of contextual, task-irrelevant information (e.g., Baskin-Sommers et al., 2011; Hiatt et al., 2004; Newman, 1998; though see R. J. R. Blair \& Mitchell, 2009 , for an alternative perspective), even when the information is motivationally relevant and typically captures attention (e.g., Newman et al., 2010). As with the fear deficits in psychopathy, recent work has demonstrated that these early selective attention deficits are more consistently linked to the affective-interpersonal dimension of psychopathy (DvorakBertsch, Curtin, Rubinstein, \& Newman, 2009; Newman et al., 2010; Sadeh \& Verona, 2008, though see BaskinSommers et al., 2011).

In contrast to these presumed early attentional deficits associated with the affective-interpersonal dimension, deficits in higher-order reasoning, executive function, and response inhibition have instead been associated with the impulsive-antisocial dimension (Baskin-Sommers, Wallace, MacCoon, Curtin, \& Newman, 2010; Sadeh \& Verona, 2008; Sellbom \& Verona, 2007). Similarly, psychophysiological research has identified an association between the impulsive-antisocial dimension and reduced P300 
amplitude - an event-related potential (ERP) index of working memory processes - on visual oddball tasks (Carlson, Thái, \& McLarnon, 2009; Venables, Patrick, Hall, \& Bernat, 2011). Thus, in contrast to the affective-interpersonal features of psychopathy, impulsive and antisocial traits appear to be characterized by heightened sensitivity to emotional stimuli, as well as deficits in working memory function. Little to no research, including ERP research, has examined the links between impulsive-antisocial traits and early attentional processes.

Though much of the extant research has examined either the emotional or the cognitive processes in psychopathy, emerging evidence from psychophysiological research has indicated that attention and emotion are not mutually exclusive processes, but rather are reciprocally interconnected and influential (e.g., K. S. Blair et al., 2007). The processing of emotional stimuli was historically thought to be a largely automatic process, because research has shown that motivationally relevant stimuli are processed quickly and interfere with the perception of nonemotional stimuli (e.g., Anderson, 2005). However, other studies have indicated that the processing of emotional information is not entirely automatic and competes for processing resources with attentional demands (Pessoa, McKenna, Gutierrez, \& Ungerleider, 2002; Pessoa, Padmala, \& Morland, 2005). For instance, functional neuroimaging research has indicated that taxing attentional resources can suppress activation in limbic regions of the brain, including the amygdala, as early as perception (e.g., Pessoa et al., 2005). Similarly, the processing of emotional stimuli (affective pictures) has been shown to increase activation in perceptual areas, such as the visual cortex (Bradley et al., 2003; Sabatinelli, Bradley, Fitzsimmons, \& Lang, 2005), suggesting that emotional stimuli reciprocally influence attentional processes. On the basis of research implicating affect-related regions of the brain in the modulation of early attention, and vice versa, it is plausible that the emotional and attentional deficits observed in psychopathy are dually operational and mutually influential (e.g., R. J. R. Blair \& Mitchell, 2009; Newman et al., 2010). Consequently, in the present study we examined the potential interactive effects of the purported emotional and attentional deficits associated with the psychopathy dimensions.

\section{Present study}

The goal of the present study was to test the hypothesis that attentional and emotional processes, and their interactive effects, are important for understanding distinct psychopathic deficits. To test this hypothesis, we examined ERPs and FPS using a modified version of the International Affective Picture System (IAPS; Lang, Bradley, \& Cuthbert, 1997) picture-viewing paradigm. ERPs were used to examine the neural processing patterns preceding engagement of the defensive fear response measured via FPS. This type of assessment to unpack the mechanisms promoting psychopathic deficits in emotional reactivity has never been conducted in terms of the IAPS paradigm, a seminal paradigm in establishing psychopathic deficits in fear.

An additional contribution of this study involves the use of a modified IAPS paradigm to disentangle the emotional and attentional characteristics of the stimuli that elicit the FPS; this confound has yet to be examined in normative or clinical populations. According to Bradley, Hamby, Low, and Lang (2007), emotion and perceptual complexity are often confounded in the typical IAPS images used to study FPS, because emotional slides are more often visually complex (e.g., mutilation scenes) than are neutral slides (e.g., a chair). A confound of emotion and perceptual load is problematic for interpreting the deficits in FPS documented in psychopathy, because the reduced FPS could reflect an early selection bias or bottleneck due to the visual complexity of emotional slides, deficient emotionality, or an interaction of these processes. For example, if an attentional bottleneck limits the ability of psychopathic individuals to process contextual information (e.g., Baskin-Sommers et al., 2011), they might fail to process the emotional content of the pictures when attentional resources are consumed by the complexity of the pictures. To eliminate this confound, the present study used neutral and unpleasant IAPS slides (emotion manipulation), with equal numbers of slides in each emotion category rated high and low in perceptual complexity (complexity manipulation). The focus of the present study was to examine deficits in defensive reactivity in particular, given that the majority of research on psychopathy has emphasized the role of fearlessness in the development of the disorder (e.g., the low-fear hypothesis: Lykken, 1957). ${ }^{1}$ According to the research that has examined the triad of valences, emotion modulation of the startle reflex in relation to pleasant slides would not have been expected to vary as a function of either psychopathy dimension (e.g., Vaidyanathan et al., 2011), and thus pleasant pictures were not included in the present study.

The experimental paradigm and examples of the picture stimuli are presented in Fig. 1. The combination of ERP and startle reflex methodologies in the present study provides a unique opportunity, with excellent temporal resolution, to examine the distinct contributions of brain processes over time to the processing of the IAPS stimuli, which have been widely utilized to study emotional processing. The visual N1 (VN1) to picture onset was examined in order to index

\footnotetext{
${ }^{1}$ Pleasant slides were excluded from the study as a way to reduce the number of trials and the duration of the task from those aspects of Bradley et al.'s (2007) original design. This was appropriate, given the use of a clinical sample.
} 
Fig. 1 Time course of the dependent variables within a trial and examples of picture stimuli

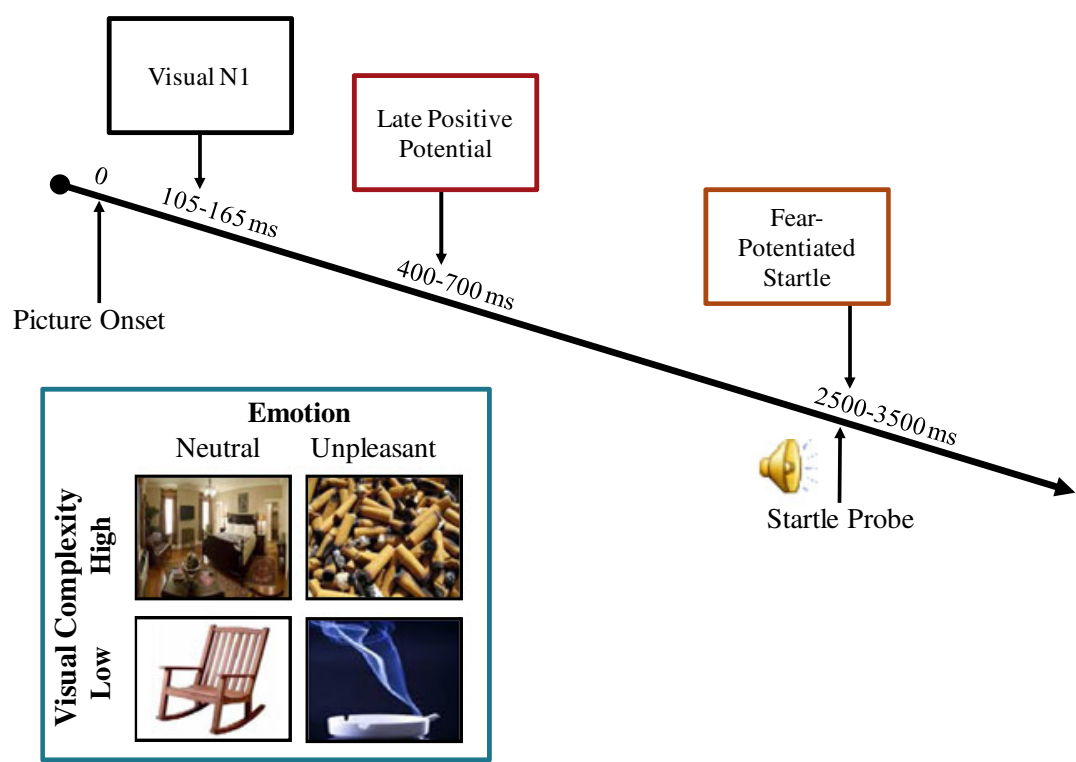

early attentional orienting to picture stimuli (Hillyard \& Anllo-Vento, 1998; Luck, Heinze, Mangun, \& Hillyard, 1990) and was expected to be larger for the high- than for the low-complexity pictures, because high-complexity images require additional attentional resources for processing their detail (Bradley et al., 2007). VN1 was used to assess selective attention abnormalities in psychopathy, with affective-interpersonal traits potentially related to heightened VN1 to high- versus low-complexity images due to hypothesized deficits in selective attention (Baskin-Sommers et al., 2011; Newman, 1998).

The late positive potential (LPP), a P3-like late positivegoing waveform, is thought to reflect a combination of processing the emotional significance of stimuli (e.g., LPP increases as picture arousal increases; Cuthbert, Schupp, Bradley, Birbaumer, \& Lang, 2000; Olofsson, Nordin, Sequeira, \& Polich, 2008; Schupp et al., 2000) and late selective attention processing (e.g., cognitive appraisal and persisting perceptual analysis of emotional stimuli; Cuthbert et al., 2000; Hajcak \& Nieuwenhuis, 2006; Schupp, Junghöfer, Weike \& Hamm 2004). Thus, it provides a valuable measure of engagement with emotional stimuli, as an assessment of both motivational significance and attentional allocation, that is relatively unaffected by early attentional processes. The LPP was used to assess later attentional allocation and sensitivity to motivationally significant stimuli, with the affective-interpersonal and impulsive-antisocial dimensions expected to relate to deficient and enhanced processing of emotion, respectively.

On the basis of research that has suggested that FPS is modulated by both attentional demands and emotional processing (Cuthbert, Schupp, Bradley, McManis, \& Lang, 1998; Newman et al., 2010), the FPS was expected to reflect the interactive effects of attentional and emotional processes associated with the affective-interpersonal dimension. To date, no published research has examined how perceptual complexity in the IAPS stimuli affects the startle response in normative or clinical populations. Thus, in addition to the psychopathy-related deficits, the present study may help elucidate whether attentional load moderates startle reactivity in response to the IAPS picture stimuli.

\section{Hypotheses}

Picture complexity On the basis of previous research (e.g., Dvorak-Bertsch et al., 2009; Newman et al., 2010; Sadeh \& Verona, 2008), scores on the affective-interpersonal dimension of psychopathy were expected to be positively associated with attentional orienting to the pictures, measured via the VN1. In particular, we expected perceptual complexity to tax more of the attentional resources of individuals high on the affective-interpersonal dimension than of those low on this dimension, resulting in a positive association between the affective-interpersonal dimension and the effect of picture complexity on VN1. In contrast, the impulsive-antisocial dimension was not expected to moderate neural processing of picture complexity, given that high perceptual load does not appear to engender cognitive deficits in individuals high on the impulsive-antisocial dimension (Sadeh \& Verona, 2008).

Emotional processing Individuals high in affective-interpersonal traits are less affected by threatening stimuli and attend less to their emotional states than do individuals who score low on this dimension (e.g., Benning et al., 2005; Gordon et al., 2004; Malterer, Glass, \& Newman, 2008; Patrick et al., 1993; Vaidyanathan et al., 2011). In contrast, there is preliminary evidence to suggest that individuals 
with elevated levels of impulsive and antisocial traits show enhanced processing and cognitive elaboration of motivationally relevant stimuli relative to those who score low on this dimension (Buckholtz et al., 2010; Gordon et al., 2004; Verona, Sprague, \& Sadeh, in press). Thus, we predicted that the affective-interpersonal dimension would correlate negatively, and the impulsive-antisocial dimension positively, with emotion modulation of the LPP.

Attention-emotion interactions Given that FPS is modulated by attentional demands and emotional reactivity, we expected attentional and emotional deficits to have an interactive effect on FPS magnitude for the affective-interpersonal dimension. Specifically, we predicted a three-way interaction between the affective-interpersonal dimension, picture complexity, and picture emotion for FPS, such that deficits in FPS would emerge only when the hypothesized weak defensive fear response had to compete with the attentional demands of the high-complexity pictures. Research has indicated that the impulsive-antisocial dimension is not associated with enhanced potentiation of the startle reflex (see, e.g., Benning et al., 2005), and it was not expected to moderate startle reflex magnitude in the present study.

\section{Method}

Participants

A group of 63 adults (male: $n=52,82.5 \%$ ) from the ages of 18-50 years participated (see Table 1 for demographic information). Individuals from a separate assessment study were invited to participate on the basis of their psychopathy scores and mental health diagnoses. The sample was recruited from criminal justice system agencies (e.g., probation, parole, and local county jails) and via newspaper advertisements targeting individuals with a history of justice system involvement. Individuals with a lifetime diagnosis of a psychotic (non-substance-induced) or bipolar disorder, determined using the Structured Clinical Interview of the DSM-IV-TR (First, Spitzer, Gibbon, \& Williams, 2002), were ineligible to participate, because the acute effects of these disorders can artificially inflate scores on measures of psychopathy. The proportions of men and women invited to participate were based on the prevalence rates of psychopathy for each gender in forensic settings (Louth, Hare, \& Linden, 1998; Vitale, Smith, Brinkley, \& Newman, 2002).

\section{Measures}

The Psychopathy Checklist: Screening Version (PCL:SV; Hart, Cox, \& Hare, 1995) is a 12-item measure designed
Table 1 Descriptive statistics $(N=63)$

\begin{tabular}{lll}
\hline Age & $M(S D)$ & Min/Max \\
& $33.2(8.4)$ & $18 / 50$ \\
\hline Gender & Frequency & $\%$ \\
Men & 52 & 82.5 \\
Women & 11 & 17.5 \\
Ethnicity & Frequency & $\%$ \\
African-American & 31 & 49.2 \\
Caucasian & 25 & 39.7 \\
Biracial & 3 & 4.8 \\
Hispanic & 2 & 3.2 \\
Native-American & 2 & 3.2 \\
Education & Frequency & $\%$ \\
Less than HS & 10 & 15.9 \\
HS diploma & 16 & 25.4 \\
Technical school/Some college & 32 & 50.8 \\
Bachelor's degree & 4 & 6.3 \\
WAIS-III & $M(S D)$ & Min/Max \\
Vocabulary & $10.0(3.3)$ & $4 / 18$ \\
Block Design & $9.5(2.7)$ & $4 / 18$ \\
WAIS Composite & $0(0.8)$ & $-1.2 / 2.5$ \\
PCL:SV & $M(S D)$ & Min/Max \\
Affective-Interpersonal & $5.3(3.1)$ & $0 / 11$ \\
Impulsive-Antisocial & $7.4(2.7)$ & $1 / 12$ \\
\hline & & \\
\hline
\end{tabular}

WAIS-III, Wechsler Adult Intelligence Scale-Third Edition (Wechsler, 1997); the possible scores for the Vocabulary and Block Design subtests range from 1 to 19 . WAIS Composite, standardized and summed scaled scores for the Vocabulary and Block Design subtests. PCL:SV, Psychopathy Checklist: Screening Version (Hart, Cox, \& Hare, 1995); possible scores range from 0 to 12

to index psychopathic traits in samples in which prison/ psychiatric records are limited (Hart et al., 1995). Data collected from semi-structured interviews and a public criminal record search were used to rate participants on 12 psychopathic traits, which were summed to create two dimensions. The PCL:SV Affective-Interpersonal dimension consisted of superficial charm, grandiosity, deceitfulness, lack of remorse, shallow affect, and failure to accept responsibility, whereas the PCL:SV Impulsive-Antisocial dimension consisted of impulsivity, poor behavioral control, lack of goals, irresponsibility, adolescent antisocial behavior, and adult antisocial behavior (see Table 1 for the descriptive statistics). Each trait was rated on a 3-point scale ranging from 0 (Not at all characteristic) to 2 (Extremely characteristic) by trained graduate- or doctorallevel raters. Interrater reliability was evaluated in $25 \%$ of the interviews conducted in the original assessment sample $(N=465)$, and the intraclass correlations for the Affective-Interpersonal and Impulsive-Antisocial scores were .93 and .93 , respectively. 
The Vocabulary and Block Design subtests of the Wechsler Adult Intelligence Scale-Third Edition (Wechsler, 1997) were administered to obtain an estimate of each participant's overall intellectual abilities. A composite estimate of intellectual function was created by standardizing and summing the two subtest scores (see Table 1 for descriptive statistics). This composite was used as a covariate in analyses to ensure that findings could not be attributed to individual differences in overall intellectual ability.

\section{Picture-viewing paradigm}

Participants completed a computer task in which they viewed neutral and unpleasant IAPS stimuli that were matched for visual complexity. Visual-complexity determinations were based on Bradley et al. (2007), who classified images as having either a clear figure-ground composition or a complex scene composition (i.e., images that did not have a constant background or prominent central figure). These classifications were verified by independent raters and computerized analysis of the spatial frequency and contrast of the images. The four conditions depicted in the inset panel in Fig. 1 (neutral-low, neutral-high, unpleasantlow, and unpleasant-high) were each represented by 32 pictures, resulting in a total of 128 pictures. $^{2}$ Nine buffer slides (with no acoustic startle probe) were also presented to reduce the predictability of the startle probe. Participants viewed the pictures in 32 subsets of four pictures (one from each condition) that were organized in one of two presentation orders (the mean serial positions for Order 1/Order 2 are as follows: neutral-low complexity, 60.9/59.3; neutral-high complexity, 62.7/62.9; unpleasant-low complexity, 62.7/ 62.9; and unpleasant-high complexity, 61.2/62.8) (Fig. 2). Presentation order was counterbalanced across participants. Pictures were presented for $4.75 \mathrm{~s}$, with an average intertrial interval of $12 \mathrm{~s}$.

Acoustic startle probes (each a $105-\mathrm{dB}, 50-\mathrm{ms}$ burst of white noise with an instantaneous rise time) were administered binaurally over earphones to elicit a blink response. The onset of the startle probe varied across three delays

\footnotetext{
2 The following IAPS pictures were selected from Bradley et al. (2007): Low complexity Neutral:2190/2200/2210/2214/2215/2221/ $2230 / 2270 / 2271 / 2280 / 2440 / 2495 / 2516 / 2570 / 2810 / 2830 / 6150 / 7010 /$ 7100/7110/7130/7140/7150/7175/7190/7211/7224/7233/7235/7490/ 7705/7950. Unpleasant: 1050/1120/1300/1930/2120/2520/2800/3030/ $3100 / 3168 / 3170 / 3181 / 3266 / 3400 / 3550 / 5970 / 6020 / 6230 / 6250 / 6260 /$ 6300/6370/9006/9008/9010/9180/9405/9432/9440/9560/9561/9800. High complexity Neutral: 2206/2381/2383/2410/2480/2514/2518/ 2580/2749/2752/2850/2870/3210/5120/5395/5455/5731/6000/7180/ 7205/7234/7495/7496/7500/7510/7550/7560/7590/7595/7700/9210/ 9700. Unpleasant: 1051/1280/1303/2205/2590/2691/2730/3015/3064/ $3500 / 3530 / 5971 / 6211 / 6212 / 6821 / 6830 / 6831 / 6838 / 7380 / 9001 / 9090 /$ 9102/9181/9252/9290/9300/9470/9480/9592/9611/9912/9921.
}

from picture onset $(2.5,3.0$, or $3.5 \mathrm{~s})$ and also occurred intermittently during the interpicture interval $(1.0,1.5$, or $2.0 \mathrm{~s}$ following picture offset).

Psychophysiological measures

ERPs Electroencephalograms (EEGs) were recorded from the scalp using a Lycra stretchable cap with $\mathrm{Ag}-\mathrm{AgCl}$ electrodes placed on the head (ElectroCap International, Inc; Eaton, OH). Each electrode site was mildly abraded and electrode paste applied. The international 10-20 system was used for electrode placement, and the electrode impedance for all channels was kept below $20 \mathrm{k} \Omega$. The EEG data for 1 participant were excluded as a result of high electrode impedance. To record eye movements for offline blink correction, two 4-mm $\mathrm{Ag}-\mathrm{AgCl}$ electrodes were placed above and below the pupil of the right eye, and two electrodes were placed near the right and left outer canthi, measuring vertical and horizontal electrooculograms (EOGs), respectively. EEGs and EOGs were amplified using Neuroscan Synamps2 (Neuroscan Compumedics, Charlotte, NC) and bandpass-filtered from 0.1 to $100 \mathrm{~Hz}$. Analog signals were digitized online at $2000 \mathrm{~Hz}$ using a 24-bit A/D converter. The left mastoid served as the reference electrode during recording.

Fear-potentiated startle Two 4-mm $\mathrm{Ag}-\mathrm{AgCl}$ electrodes were placed on the orbicularis oculi muscle under the left eye to record the startle reflex. Electrode impedance was kept below $10 \mathrm{k} \Omega$, and the electromyogram (EMG) was digitized online at $2000 \mathrm{~Hz}$ using a 24-bit A/D converter.

\section{Data reduction}

ERPs The EEG was visually checked for muscle movement and other artifacts. Contaminated epochs were removed manually. Eye movements were removed using a regression-based blink correction procedure in Neuroscan Edit 4.3. The EEG data were re-referenced offline using an average mastoid reference derivation. The data were digitally bandpass filtered from 0.1 to $30 \mathrm{~Hz}$ (half-amplitude cutoff; 12-dB/octave roll-off) to reduce the noise in the EEG channels generated by the EMG (Edgar, Stewart, \& Miller, 2005). Artifact-free epochs were extracted from $200 \mathrm{~ms}$ before until $1,500 \mathrm{~ms}$ after picture onset. The data were baseline adjusted (200 ms before stimulus onset) prior to the averaging and analysis. The average number of useable trials for each condition was as follows: neutral-low complexity, $M=30.8$, $S D=1.8$; neutral-high complexity, $M=31.0, S D=1.4$; unpleasant-low complexity, $M=30.5, S D=1.8$; and unpleasant-high complexity, $M=30.8, S D=1.7$. 
A peak scoring window of $50 \mathrm{~ms}$ for $\mathrm{VN} 1$ was centered on the grand-average peak of the first negative-going waveform that occurred after $100 \mathrm{~ms}$ following picture onset, which was determined on the basis of visual inspection of the ERP components. VN1 was scored as the most negative peak 105-165 ms post-picture-onset for each sensor and then averaged over occipital sites $(\mathrm{O} 1, \mathrm{Oz}$, and $\mathrm{O} 2)$. The scoring window for the LPP component was based on the previous work (Bradley et al., 2007), and this window was consistent with individual-participant average waveforms in the present sample. LPP was scored as the average amplitude from 400 to $700 \mathrm{~ms}$ post-picture-onset for each sensor and then averaged over the centroparietal sites $(\mathrm{Cz}, \mathrm{CPz}$, and $\mathrm{Pz}$ ). ERP waveforms were averaged across trials within each emotion-complexity category. Participants with amplitude values greater or less than three standard deviations from the mean for a particular component were Winsorized to 3 or -3 , respectively, to reduce the influence of outliers.

Fear-potentiated startle Epochs from the raw orbicularis oculi EMG signal were extracted from $50 \mathrm{~ms}$ before to $100 \mathrm{~ms}$ after the startle probe onset. In accordance with the recommendations of Blumenthal et al. (2005), the raw EMG signal was filtered to reduce noise using a high-pass filter ( $30 \mathrm{~Hz}$, half-amplitude cutoff; 24-dB roll-off), rectified, and then smoothed using a low-pass filter $(30 \mathrm{~Hz}$, halfamplitude cutoff; 24-dB roll-off). The EMG signal was also baseline adjusted offline ( $50 \mathrm{~ms}$ before probe onset). Startle responses were scored as the peak magnitude of the eyeblink response $21-95 \mathrm{~ms}$ following probe presentation using a computer-scoring program and verified by visual inspection. Trials were rejected if the baseline period was contaminated with noise, if the blink began before $21 \mathrm{~ms}$, or if the eye-blink response was contaminated with noise. To ensure that individual differences in absolute blink magnitude and response variability could not account for the results, blink magnitude was standardized across trials within each participant using a $z$ transformation (Blumenthal et al., 2005). Standardized blink magnitudes greater than 3 or less than -3 were Winsorized to 3 or -3 , respectively, to reduce the influence of outliers (Benning et al., 2005; Patrick et al., 1993). Participants' data were included in analyses if less than $30 \%$ of the trials were rejected due to noise and there were at least six usable startle responses for each condition. The data for 3 participants were removed for not meeting the minimum number of acceptable trials.

\section{Data analytic strategy}

Dependent variables were analyzed separately in repeated measures analyses of variance (ANOVAs) with Emotion (neutral, unpleasant) and Complexity (low, high) entered as the within-subjects factors. The effects of the psychopathy dimensions were examined by entering the raw PCL:SV Affective-Interpersonal and PCL:SV Impulsive-Antisocial scores as between-subjects continuous variables and gender and the WAIS-III composite variable as covariates in analyses. ${ }^{3,4}$ When the analyses indicated moderation by psychopathy, scatterplots were examined to ensure that the results were not accounted for by bivariate outliers.

For follow-up analyses, indices for picture emotion (unpleasant trials - neutral trials) and picture complexity (highcomplexity trials - low-complexity trials) were calculated. For ease of interpretation, the effects for VN1, a negative-going waveform, were calculated in the opposite direction (picture emotion, neutral trials - unpleasant trials; picture complexity, low complexity - high complexity).

\section{Results}

The top of Table 2 reports the sample means for FPS, VN1, and LPP by conditions.

\section{Event-related brain potentials}

Visual N1 Grand-average waveforms for VN1 to picture onset are presented in Fig. 2. VN1 to picture onset varied as a function of picture complexity, $F(1,62)=25.01, p<$ $.001, \eta_{\mathrm{p}}{ }^{2}=.29$, with high-complexity pictures eliciting more negativity $(M=-2.1, S D=2.8)$ than did low-complexity pictures $(M=-1.2, S D=2.55)$. This finding suggests that participants allocated more attention to processing highthan to processing low-complexity pictures. The main effect of picture emotion and the Complexity $\times$ Emotion interaction were not significant for VN1.

Main effects of the PCL:SV dimensions emerged for VN1. PCL:SV Affective-Interpersonal was positively associated with VN1 amplitude to all pictures, $r=-.26$ (greater negative deflection), $F(1,58)=4.1, p=.047, \eta_{\mathrm{p}}{ }^{2}=.07$, suggesting the presence of greater attentional orienting among individuals high than among those low on this

\footnotetext{
$\overline{{ }^{3} \text { Given that the }}$ psychopathy dimensions were moderately correlated $(r=$ .62), separate analyses were conducted using each PCL:SV dimension (instead of simultaneously) to examine whether the results for the psychopathy dimensions reflected suppressor effects. All of the effects reported for analyses conducted with the psychopathy dimensions entered simultaneously were also present when each psychopathy dimension was examined separately, with the exception of the main effects of PCL:SV Affective-Interpersonal and Impulsive-Antisocial reported for VN1 amplitude, which were no longer significant. For the sake of parsimony, results for the analyses conducted with the psychopathy dimensions entered simultaneously are reported in the Results section.

${ }^{4}$ Excluding the WAIS-III composite as a covariate did not change the results.
} 
Table 2 Dependent variable means (standard deviations in parentheses; top) and correlations of psychopathy dimensions with dependent variables by condition (bottom)

\begin{tabular}{llll}
$\begin{array}{l}\text { Neutral-Low } \\
\text { Complexity }\end{array}$ & $\begin{array}{l}\text { Neutral-High } \\
\text { Complexity }\end{array}$ & $\begin{array}{l}\text { Unpleasant-Low } \\
\text { Complexity }\end{array}$ & $\begin{array}{l}\text { Unpleasant-High } \\
\text { Complexity }\end{array}$ \\
\hline
\end{tabular}

\section{Means and Standard Deviations}

Fear potentiated startle standardized

$\begin{array}{cc}-.04(.13) & -.08(.13) \\ 17.2(19.7) & 16.7(19.3) \\ -0.95(2.8) & -2.1(2.8) \\ 1.4(3.0) & 0.4(3.0)\end{array}$

$.04(.13)$

$-.08(.14)$

Fear potentiated startle raw

$0.4(3.0)$

$18.1(19.6)$

$16.7(19.3)$

Visual N1

$-1.5(2.60)$

$-2.2(3.0)$

Late positive potential

\section{Simple-Effect Correlations}

Fear-Potentiated Startle Standardized

PCL:SV Affective-interpersonal

$\begin{array}{rrrr}-.07 & .18 & -.03 & -.24 \\ .06 & -.22 & .21 & .08\end{array}$

PCL:SV Impulsive-antisocial

$2.8(4.3)$

$1.2(3.8)$

Visual N1

PCL:SV Affective-interpersonal

$-.26^{*}-.16$

PCL:SV Impulsive-antisocial

Late Positive Potential

PCL:SV Affective-interpersonal

PCL:SV, Psychopathy Checklist: Screening Version (Hart, Cox, \& Hare, 1995). ${ }^{*} p<.05$

Fig. 2 Grand-average waveforms for visual N1 (VN1; O1, $\mathrm{Oz}$, and $\mathrm{O} 2$ electrodes) and late positive potential (LPP; $\mathrm{Cz}, \mathrm{CPz}$, and $\mathrm{Pz}$ electrodes) by condition
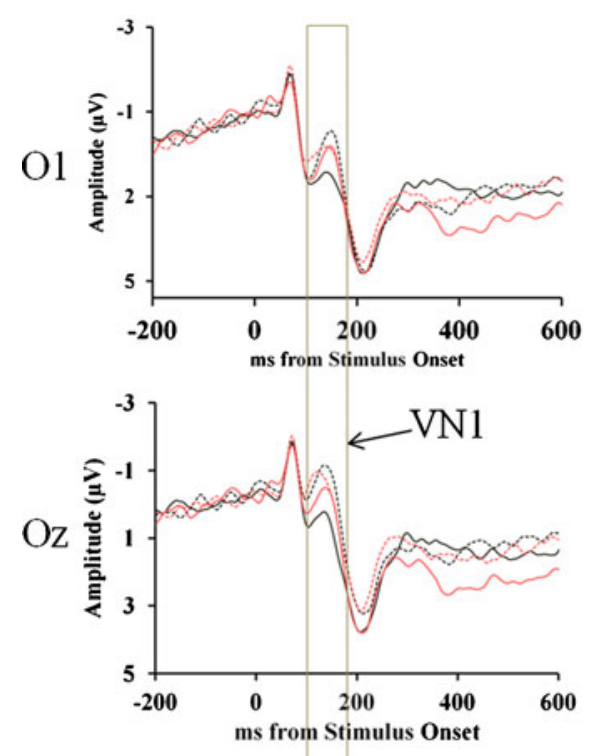

$\mathrm{CPz}$

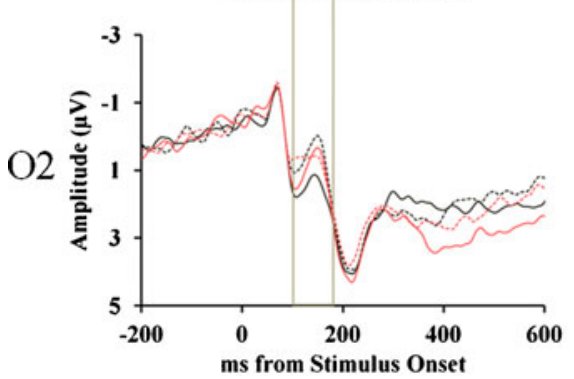

$\mathrm{Cz}$

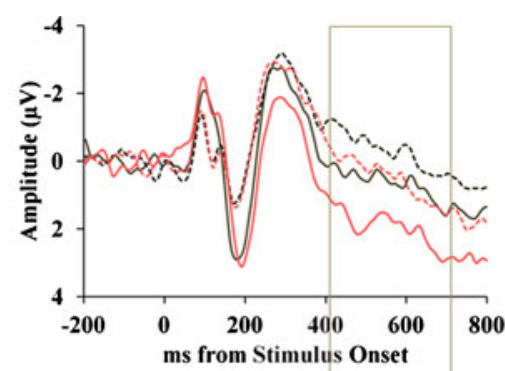

Pz
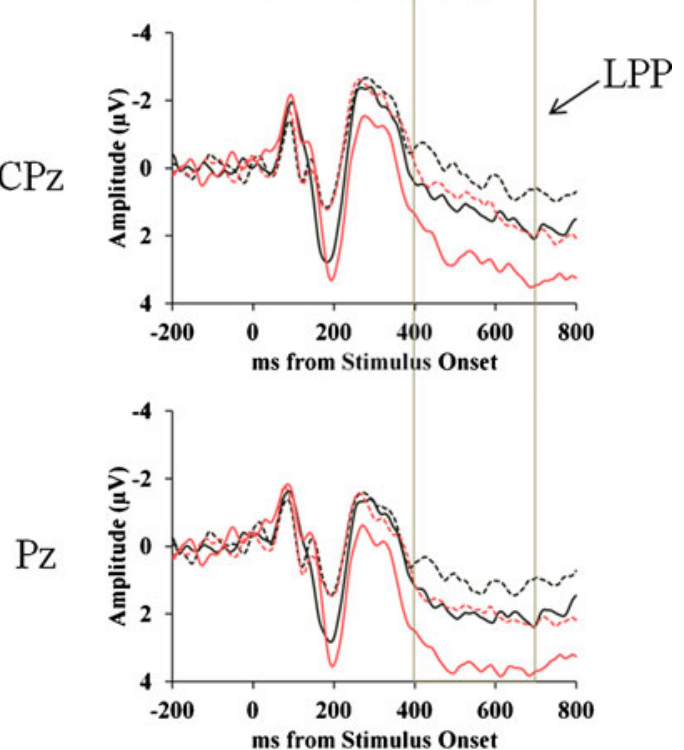
psychopathy dimension. In contrast, PCL:SV ImpulsiveAntisocial was negatively associated with VN1 amplitude, $r=.30$ (less negative deflection), $F(1,58)=5.5, p=.022$, $\eta_{\mathrm{p}}{ }^{2}=.09$, indicating that individuals high in these traits allocated less attention to processing the pictures overall than did individuals low on this psychopathy dimension.

Psychopathy interactions with picture emotion and picture complexity were also found. First, a three-way PCL:SV Affective-Interpersonal $\times$ Emotion $\times$ Complexity interaction emerged for VN1 amplitude, $F(1,58)=7.3, p=.009$, $\eta_{\mathrm{p}}{ }^{2}=.11$. Follow-up analyses indicated that PCL:SV Affective-Interpersonal moderated the effect of picture emotion on VN1 amplitude when the pictures were high in complexity, $F(1,58)=5.4, p=.024, \eta_{\mathrm{p}}{ }^{2}=.09$, but not when they were low in complexity $(p>.13)$. As depicted in Fig. 3 (top), PCL:SV Affective-Interpersonal was associated with greater orienting to unpleasant than to neutral pictures when the images were high in complexity, $r=.29$, but with the opposite effect when images were low in complexity, $r=-.20$ (see the simple-effect correlations reported in the bottom part of Table 2). This interaction suggests that individuals high in affective-interpersonal traits required more attentional resources to process emotion when the pictures were visually complex.

Second, PCL:SV Impulsive-Antisocial interacted with picture complexity, $F(1,58)=5.6, p=.021, \eta_{\mathrm{p}}{ }^{2}=.09$, reflecting less differentiation between complex and simple pictures in VN1 amplitude as scores on the impulsiveantisocial dimension increased, $r=-.29$. Thus, individuals high on PCL:SV Impulsive-Antisocial appeared to be less affected by the perceptual-complexity manipulation than were individuals low on this psychopathy dimension. PCL: SV Impulsive-Antisocial did not moderate picture emotion or the Emotion $\times$ Complexity interaction.

Late positive potential Grand-average waveforms for the LPP response to picture onset are presented in Fig. 2. Picture emotion and picture complexity affected LPP amplitudes, $F_{\mathrm{S}}(1,61)>24.37, p \mathrm{~s}<.001, \eta_{\mathrm{p}}{ }^{2} \mathrm{~s}=.29$, which were larger to unpleasant $(M=1.98, S D=3.85)$ than to neutral $(M=.90, S D=.2 .79)$, and to lowcomplexity $(M=2.10, S D=3.55)$ than to highcomplexity $(M=0.78, S D=3.27)$, pictures. These relationships were qualified by an Emotion $\times$ Complexity interaction, $F(1,61)=4.47, p=.039, \eta_{\mathrm{p}}{ }^{2}=.07$. Although differences in LPP amplitudes emerged for unpleasant versus neutral pictures regardless of picture complexity, the magnitude of the picture emotion effect was larger for lowcomplexity $(M=1.38, S D=2.20)$ than for high-complexity $(M=0.78, S D=1.88)$ pictures. This suggests that unpleasantness depicted in simple figure-ground images (e.g., a gun) was more salient than unpleasantness depicted in complex scenes (e.g., an angry mob).
As hypothesized, a PCL:SV Affective-Interpersonal $\times$ Emotion interaction emerged for LPP amplitude, $F(1,57)=$ $5.17, p=.027, \eta_{\mathrm{p}}{ }^{2}=.08$. This interaction reflected a negative association between this psychopathy dimension and the magnitude of the LPP emotion effect, $r=-.29$. That is, high levels of the affective-interpersonal features of psychopathy were associated with reduced cognitive processing of the motivational significance of the unpleasant pictures. No other significant main or interactive effects on LPP amplitude were found for the PCL:SV Affective-Interpersonal or Impulsive-Antisocial factors.

\section{Fear-potentiated startle}

Replicating previous work, startle magnitude varied as a function of picture emotion, $F(1,59)=4.14, p=.046, \eta_{\mathrm{p}}{ }^{2}=.07$, with unpleasant pictures $(M=.01, S D=.09)$ eliciting greater startle reflex responses than did neutral pictures $(M=-.05$, $S D=.09$ ). Consistent with research demonstrating that the startle reflex is affected by attentional load, startle magnitude was also affected by picture complexity, $F(1,59)=16.42, p<$ $.001, \eta_{\mathrm{p}}{ }^{2}=.22$, with low-complexity images $(M=.02, S D=$ $.08)$ eliciting greater startle responses on average than did high-complexity images $(M=-.06, S D=.08) .^{5}$

The predicted PCL:SV Affective-Interpersonal $\times$ Emotion $\times$ Complexity three-way interaction emerged, $F(1,55)=4.29$, $p=.043, \eta_{\mathrm{p}}{ }^{2}=.07$. Further analysis revealed that the PCL:SV Affective-Interpersonal dimension interacted with picture emotion for high-complexity, $F(1,55)=4.06, p=.049, \eta_{\mathrm{p}}{ }^{2}=.07$, but not low-complexity $(p>.84)$, pictures. As is illustrated in Fig. 3 (bottom), PCL:SV Affective-Interpersonal was negatively associated with FPS magnitude to high-complexity pictures, $r=-.26$, but did not modulate FPS magnitude to lowcomplexity pictures, $r=.03$. Thus, although the affectiveinterpersonal traits were associated with more effortful early orienting in $\mathrm{VN} 1$ to emotional pictures when complexity was high, this dimension was associated with reduced defensive activation to unpleasant pictures also high in visual complexity. As expected, PCL:SV Impulsive-Antisocial did not moderate FPS amplitude. No other main or interaction effects emerged for the PCL:SV Affective-Interpersonal or ImpulsiveAntisocial factors.

\footnotetext{
${ }^{5}$ Supplementary analyses revealed a significant main effect of block for the startle response, $F(3,57)=76.5, p=.001$, with the startle magnitude decreasing over the course of the experiment. This represents the typical habituation of the startle response across multiple presentations. There was also a Block $\times$ Picture Emotion interaction, $F(3,57)=4.11, p=01$, such that the size of the startle effect increased over the four blocks for the negative pictures (Block $1=-.08, S D=$ .39 ; Block $2=.02, S D=.28$; Block $3=.10, S D=.31$; Block $4=.13$, $S D=.31)$
} 
Fig. 3 Moderation of (a) visual N1 (VN1) amplitude and (b) fear-potentiated startle by the PCL:SV affective-interpersonal dimension. ${ }^{*} p<.05$
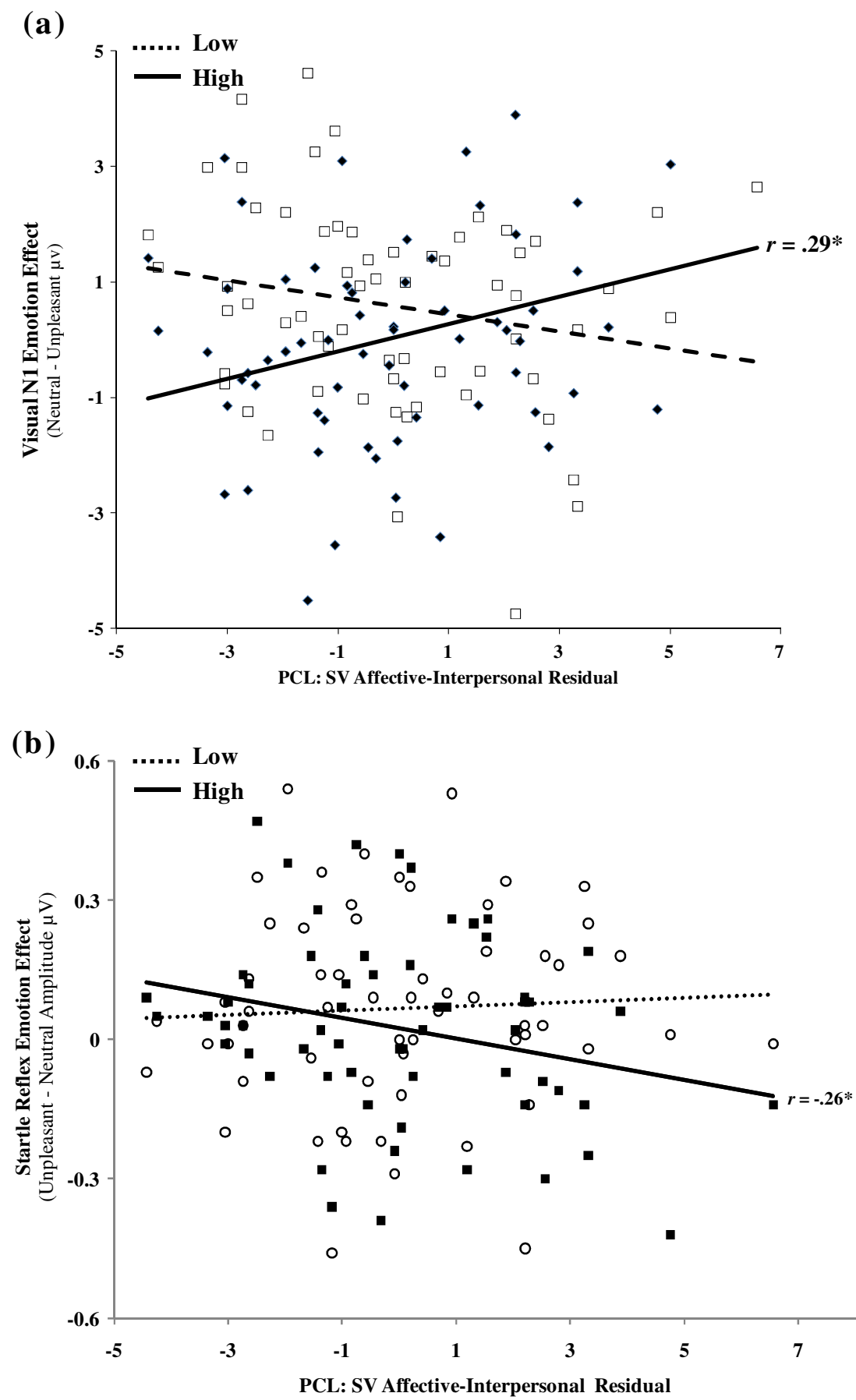

\section{Discussion}

Research has made great strides in explicating how dysfunction in emotional systems contributes to the functional impairments associated with psychopathy. However, this research has largely been conducted without attending to how these emotional deficits may contribute to, or interact with, attentional abnormalities, despite evidence suggesting the presence of such deficits (cf. Newman, 1998, though see recent work by Newman et al., 2010, and Baskin-Sommers et al., 2011). The results of the present study indicate that, although emotional processing deficits are indeed evident in psychopathy, these effects are moderated by the perceptual properties of the stimuli. This implicates cognition-emotion interactions as potentially important for understanding the full range of deficits associated with the affective-interpersonal traits of psychopathy. The analyses also revealed potential deficits in early attention associated with the impulsiveantisocial dimension, an unexpected finding that might advance our knowledge of the cognitive deficits 
associated with externalizing disorders. More broadly, the present findings are consistent with a growing neuroscience literature that indicates that emotion is not independent of attention, but rather that these systems are reciprocally interconnected and bidirectionally influential as early as perception (Bradley et al., 2003; Pessoa et al., 2005; Sabatinelli et al., 2005).

\section{Affective-interpersonal dimension}

Research on the affective-interpersonal features of psychopathy has found evidence that this dimension is associated with deficits in emotional processing, particularly a weak fear response to unpleasant stimuli (Benning et al., 2005; Patrick et al., 1993; Vaidyanathan, et al., 2011), as well as an increased sensitivity to stimuli that tax attentional resources (Baskin-Sommers et al., 2011; Newman et al., 2010; Sadeh \& Verona, 2008). Consistent with both sets of data, the affective-interpersonal dimension moderated attentional and emotional processing in VN1, LPP, and FPS in the present study. Importantly, these results have the potential to advance etiological theories of the affective-interpersonal dimension by providing new evidence that proposed emotional and attentional mechanisms are not only dually operational but also interactive in nature.

As predicted, the affective-interpersonal dimension evidenced sensitivity to perceptual complexity for VN1, indicating greater allocation of attentional resources when images were complex. However, the relationship that emerged was, unexpectedly, a cognition-emotion interaction rather than a simple effect of picture complexity. Specifically, results for the VN1 indicated that attentional resources increased when processing unpleasant versus neutral images as a function of the affective-interpersonal dimension, but only for visually complex images. These results suggest that more attentional resources were being allocated to try to interpret or decipher the negative emotional content when it was obscured by high visual complexity. Despite allocating more early attention to deciphering high-complexity unpleasant pictures, later modulation of the LPP as a function of picture emotion diminished as scores on the affective-interpersonal dimension increased; however, this effect did not vary as a function of picture complexity, as it did for VN1. Thus, individuals high on the affective-interpersonal dimension ultimately showed reduced cognitive appraisal of the motivational significance of both low- and high-complexity unpleasant images at later stages of categorization (LPP). Taken together, these results are consistent with previous theorizing implicating both deficient attentional resources (Baskin-Sommers et al., 2011) and a reduced sensitivity to emotional stimuli at both early perception and later elaboration in psychopathy (Levenston, Patrick, Bradley, \& Lang, 2000).
These dual attention-emotion deficits were also reflected in the FPS findings, our index of defensive fear reactivity. The affective-interpersonal dimension was associated with reduced FPS for high-complexity unpleasant pictures, suggesting that the visually complex stimuli attenuated defensive responding in individuals with affective and interpersonal deficits of psychopathy. Across the ERP and FPS measures, the present findings suggest that individuals high on affectiveinterpersonal traits were less affected by the motivational significance of the high-complexity unpleasant images (LPP and FPS), even though they allocated more resources to them at perception (VN1).

The present study cannot definitively disentangle the underlying processes driving the observed cognition-emotion interactions. However, the data from this study and previous work strongly implicate both attentional and emotional processes as being aberrant in psychopathy. The present findings suggest that perceptual processing is taxed (VN1) and emotional reactivity is weakened (FPS) in individuals high in affective-interpersonal traits by stimuli that engage both attentional and affective systems. There is also evidence for diminished attention to and cognitive elaboration of emotional stimuli (LPP) among individuals high in affectiveinterpersonal traits. Thus, we propose that deficits in defensive reactivity emerge as a result of deficient attentional resources interacting with a weak prioritization of motivationally relevant stimuli by emotion systems. This interpretation integrates extant theories that have posited deficits in top-down attentional bottlenecks and deficient fear responses in the affective-interpersonal features of psychopathy (e.g., Baskin-Sommers et al., 2011; R. J. R. Blair \& Mitchell, 2009; Lykken, 1957; Patrick et al., 1993).

\section{Impulsive-antisocial dimension}

The present study was not specifically developed to examine the hypothesized cognitive deficits associated with impulsive-antisocial traits. Nonetheless, the results indicated that the impulsive-antisocial dimension moderated the effect of picture complexity on VN1, which was an unanticipated finding, but one that expands our understanding of this dimension of psychopathy. The negative association of impulsivity-antisociality with VN1 picture complexity suggests that individuals high on these traits were less sensitive to the processing demands of high- versus low-complexity pictures (Bradley et al., 2007; Cuthbert et al., 1998; Luck, 2005). Such individuals do not seem to allocate the resources necessary to process more complex information. Although this is a novel finding, research has revealed that individuals with a history of alcohol dependence- - a disorder related to the impulsive-antisocial dimension via the externalizing spectrum of psychopathology (Krueger et al., 2002; Patrick, Hicks, Krueger, \& Lang, 2005)—is 
associated with reduced visual N1 amplitudes to nontarget stimuli, as well as reduced P3 amplitudes to target stimuli in oddball paradigms (Bauer \& Hesselbrock, 1999; Olbrich, Maes, Gann, Hagenbuch, \& Feige, 2000; Patterson, Williams, McLean, Smith, \& Schaffer, 1987). Thus, the diminished effect of picture complexity is consistent with findings in the broader literature on the cognitive deficits and resource allocation deficits related to externalizing traits.

This result also indicates that cognitive deficits may be observable prior to P3 in individuals with externalizing traits. In particular, the cognitive control and working memory deficits associated with impulsive and antisocial traits may be preceded in certain conditions by abnormal perceptual or early selective attention processes. As stated, reduced attentional orienting to the slides and processing of perceptual complexity might reflect a tendency of individuals high in impulsivity-antisociality to exert fewer resources to processing the details of stimuli at perception than do those low on impulsive-antisocial traits. Additional research will be needed to assess whether this attentional bias contributes to the diminished elaborated attention to novel and unexpected information observed in measures of oddball P3 in externalizing individuals (Costa et al., 2000; Iacono, Carlson, Malone, \& McGue, 2002).

Preliminary research has indicated that the impulsiveantisocial dimension is related to enhanced processing of and attention to motivationally relevant stimuli (e.g., Buckholtz et al., 2010; Gordon et al., 2004). However, this dimension did not moderate the effect of picture emotion on VN1 or LPP amplitudes, and these traits were not associated with enhanced FPS. There are several possible explanations for inconsistencies between these findings and studies that have reported that individuals high in impulsive-antisocial traits are particularly reactive to, and overallocate attentional resources to, motivationally relevant stimuli (Buckholtz et al., 2010; Derryberry \& Reed, 1994; Gordon et al., 2004; Verona et al., in press; Wallace \& Newman, 1997). First, psychophysiological studies that have measured emotional processing using hemodynamic neuroimaging measures of amygdala activity have reported increased emotional reactivity among individuals high in impulsive and antisocial traits (e.g., Davidson, Putnam, \& Larson, 2000; Gordon et al., 2004; Joseph, Liu, Jiang, Lynam, \& Kelly, 2009), whereas those that have used FPS typically have not found moderation by this psychopathy dimension (e.g., Benning et al., 2005; Patrick et al., 1993). Thus, it might be that the ERP and FPS measures used in the present study were not sensitive enough to detect the differences in emotional processing observed in the hemodynamic neuroimaging studies.

Second, it might be that individuals high in impulsiveantisocial traits do not allocate more resources to processing or attending to emotional stimuli than do other individuals, as the VN1 results suggest. Instead, they might be more sensitive to the effects of these stimuli on behavior and might have a slower return to baseline following exposure to emotional stimuli (e.g., Lorber, 2004; Sprague \& Verona, 2010; Verona et al., in press); these aberrant processes could be more evident in measures assessing arousal (e.g., skin conductance, heart rate) or emotion-induced behavioral disinhibition. To our knowledge, previous work has not examined the effects of impulsive-antisocial traits on early attention to emotional stimuli, and further research will be needed to understand these results.

Third, a large literature has suggested that individuals with temperamental similarities to individuals high in impulsive-antisociality (e.g., individuals high in neuroticism and extroversion) are particularly sensitive to positive incentives and are slower to shift attention away from rewarding or anger stimuli (e.g., Derryberry \& Reed, 1994; Wallace \& Newman, 1997). The present study did not include positive, anger-inducing, or rewarding pictures, and therefore might have excluded particularly motivationally relevant stimuli for impulsive-antisocial individuals (e.g., Buckholtz et al., 2010; Wallace \& Newman, 1997).

Implications for attentional and emotional processing

Emerging neuroscience research confirms that attention and emotion are interdependent and bidirectionally influential in clinical as well as normative populations (Baskin-Sommers et al., 2011; Pessoa et al., 2005; Sabatinelli et al., 2005). The use of ERP and startle reflex methodologies in the present study allowed for examination of how these interactive processes unfold over time. Consistent with research by Bradley et al. (2007) in an undergraduate sample, the results indicated that early attentional processing indexed with VN1 is predominately affected by manipulations of picture complexity. This attentional effect continued to be apparent in later stages of processing, including measures of emotional processing. Specifically, the effect of picture emotion on LPP amplitude decreased when participants viewed highrather than low-complexity pictures, which suggests that the unpleasantness of pictures was more salient to participants when they viewed the simple figure-ground images rather than the high-complexity scenes. Furthermore, the present study showed for the first time a picture complexity effect on startle magnitude with the IAPS stimuli, with lowcomplexity images eliciting larger blink responses on average than did high-complexity images, which suggests that the effect of attentional load on picture processing persisted for several seconds post-picture-onset. Thus, the present results underscore the importance of measuring potential perceptual and attentional effects associated with stimuli that are used to study emotional processing, since differences in the perceptual demands of the stimuli may 
moderate the salience of emotional information and/or may tax attentional resources.

In sum, these data are some of the first to test the hypothesis of the interactive effects of early attentional and emotional processing using ERPs and startle reflex in a forensic sample. Overall, the results largely replicated the effects of perceptual complexity and picture emotionality on neural processes reported in normative samples (e.g., Bradley et al., 1989; Bradley et al., 2007; Foti, Hajcak, \& Dien, 2009; Keil et al., 2002). They also elucidate the time courses of the interactive effects of perceptual, attentional, and emotional processes, which broadens our understanding of how these systems operate over time.

\section{Strengths and limitations}

The present study benefited from a forensic sample of individuals with varying levels of psychopathic traits. Psychopathy was assessed using a well-validated assessment tool (e.g., Hart et al., 1995), and the picture-viewing paradigm has been widely used to investigate the interplay of emotional and attentional processes, which increases the generalizability of the results and the reliability of the constructs assessed.

As with any investigation, however, this study has limitations that should be considered when interpreting the findings. First, the study was underpowered to investigate the potential moderating effects of gender. Although research has suggested that the abnormal selective attention and FPS documented in psychopathic men generalize to psychopathic women (Sutton, Vitale, \& Newman, 2002; Vitale, Brinkley, Hiatt, \& Newman, 2007), research on the robustness of psychopathic deficits in women is still in its infancy, and more research is needed. ${ }^{6}$ Second, the modest sample size limited the interpretation of null results, which could be driven by a lack of power to detect relationships with small effect sizes. Third, a longitudinal design will be needed to parse potential confounds associated with the use of a forensic sample, such as the influence of violencerelated head trauma and illegal substance consumption. ${ }^{7}$ Fourth, there were more simple faces depicted in the neutral/low-complexity than in the neutral/high-complexity condition, which might have affected VN1 amplitudes, according to research implicating the N170 in face

\footnotetext{
${ }^{6}$ All of the reported results remained significant when analyses were conducted with men only, with the exception of the PCL:SV AffectiveInterpersonal $\times$ Emotion $\times$ Complexity interaction for startle magnitude and the PCL:SV Impulsive-Antisocial $\times$ Complexity interaction for VN1 amplitude, which both became marginally significant $(p s=.053)$.

${ }^{7}$ Entering a composite of lifetime alcohol and substance use dependence symptoms as a covariate in analyses did not change the main and interactive effects reported for PCL:SV Affective-Interpersonal. However, the PCL:SV Impulsive-Antisocial $\times$ Picture Complexity interaction for VN1 was reduced to nonsignificance $(p<.13)$.
}

processing (e.g., Rossion \& Jacques, 2008). Future research should examine neutral-face processing as a potential moderator of emotion or complexity effects in psychopathy. Fifth, the exclusion of pleasant stimuli in the present study, which deviates from most prior work on FPS deficits in psychopathy (e.g., Patrick et al., 1993), might have induced a more continuous unpleasant mood over the course of testing. This negative mood induction could, in turn, have been responsible for activating an FPS response for individuals high in affective-interpersonal traits to the low-complexity images, despite prior work suggesting that deficient potentiation is typically present among these pictures in psychopathy (Patrick et al., 1993). This possibility needs to be examined in future work. Finally, the picture-viewing paradigm did not allow for a thorough investigation of the executive function deficits theorized as associated with the impulsive-antisocial dimension - namely, impaired cognitive control and response inhibition (e.g., Carlson et al., 2009; Sadeh \& Verona, 2008; Sellbom \& Verona, 2007; Venables et al., 2011) - and of how these processes might influence emotional processing. Identification of the distinct cognitive and emotional deficits associated with the psychopathy dimensions and the interactive effects of these processes could help elucidate distinct pathways or sets of risk factors that lead to engagement in severe and persistent antisocial behavior.

Despite these limitations, the present study advances the literature on psychopathy by providing new evidence that the disorder is not solely characterized by an emotional or attentional deficit, as historically has been assumed. Rather, the present results indicate that psychopathy is characterized by interactive cognition-emotion deficits that manifest differentially across the psychopathy dimensions.

Author note This research was supported by National Institute of Mental Health Grant F31 MH086178.

\section{References}

Anderson, A. K. (2005). Affective influences on the attentional dynamics supporting awareness. Journal of Experimental Psychology: General, 134, 258-281. doi:10.1037/0096-3445.134.2.258

Baskin-Sommers, A. R., Curtin, J. J., \& Newman, J. P. (2011). Specifying the attentional selection that moderates the fearlessness of psychopathic offenders. Psychological Science, 22, 226-234.

Baskin-Sommers, A. R., Wallace, J. F., MacCoon, D. G., Curtin, J. J., \& Newman, J. P. (2010). Clarifying the factors that undermine behavioral inhibition system functioning in psychopathy. Personality Disorders: Theory, Research, \& Treatment, 1, 203-217.

Bauer, L. O., \& Hesselbrock, V. M. (1999). P300 decrements in teenagers with conduct problems: Implications for substance abuse risk and brain development. Biological Psychiatry, 46, 263-272.

Benning, S. D., Patrick, C. J., Hicks, B. M., Blonigen, D. M., \& Krueger, R. F. (2003). Factor structure of the Psychopathic Personality Inventory: Validity and implications for clinical assessment. Psychological Assessment, 15, 340-350. 
Benning, S. D., Patrick, C. J., \& Iacono, W. G. (2005). Fearlessness and underarousal in psychopathy: Startle blink modulation and electrodermal reactivity in a young adult male community sample. Psychophysiology, 42, 753-762.

Blair, K. S., Smith, B. W., Mitchell, D. G. V., Morton, J., Vythilingam, M., Pessoa, L., \& Blair, R. J. R. (2007). Modulation of emotion by cognition and cognition by emotion. NeuroImage, $35,430-440$.

Blair, R. J. R., \& Mitchell, D. V. G. (2009). Psychopathy, attention and emotion. Psychological Medicine, 39, 543-555.

Blumenthal, T. D., Cuthbert, B. N., Filion, D. L., Hackley, S., Lipp, O. V., \& van Boxtel, A. (2005). Committee report: Guidelines for human startle eyeblink electromyographic studies. Psychophysiology, 42, 1-15. doi:10.1111/j.1469-8986.2005.00271.x

Bradley, M. M., Cuthbert, B. N., \& Lang, P. J. (1989). Startle reflex modification: Emotion or attention? Psychophysiology, 27, 513522.

Bradley, M. M., Hamby, S., Low, A., \& Lang, P. J. (2007). Brain potentials in perception: Picture complexity and emotional arousal. Psychophysiology, 44, 364-373.

Bradley, M. M., Sabatinelli, D., Lang, P. J., Fitzsimmons, J. R., King, W., \& Desai, P. (2003). Activation of the visual cortex in motivated attention. Behavioral Neuroscience, 117, 369-380. doi:10.1037/0735-7044.117.2.369

Buckholtz, J. W., Treadway, M. T., Cowan, R., Woodward, N. D., Benning, S. D., Li, R., \& Zald, D. H. (2010). Mesolimbic dopamine reward system hypersensitivity in individuals with psychopathic traits. Nature Neuroscience, 13, 419-421.

Carlson, S. R., Thái, S., \& McLarnon, M. E. (2009). Visual P3 amplitude and self-reported psychopathic personality traits: Frontal reduction is associated with self-centered impulsivity. Psychophysiology, 46, 100-113. doi:10.1111/j.1469-8986.2008.00756.x

Cleckley, H. M. (1941). The mask of sanity: An attempt to reinterpret the so-called psychopathic personality. St. Louis: Mosby.

Costa, L., Bauer, L., Kuperman, S., Porjesz, B., O'Connor, S., Hesselbrock, V., \& Begleiter, H. (2000). Frontal P300 decrements, alcohol dependence, and antisocial personality disorder. Biological Psychiatry, 47, 1064-1071. doi:10.1016/S0006-3223(99)00317-0

Cuthbert, B. N., Schupp, H. T., Bradley, M. M., Birbaumer, N., \& Lang, P. J. (2000). Brain potentials in affective picture processing: Covariation with autonomic arousal and affective report. Biological Psychology, 52, 95-111. doi:10.1016/S0301-0511(99)00044-7

Cuthbert, B. N., Schupp, H. T., Bradley, M. M., McManis, M., \& Lang, P. J. (1998). Probing affective pictures: Attended startle and probe tones. Psychophysiology, 35, 344-347.

Davidson, R. J., Putnam, K. M., \& Larson, C. L. (2000). Dysfunction in the neural circuitry of emotion regulation-A possible prelude to violence. Science, 289, 591-594.

Derryberry, D., \& Reed, M. A. (1994). Temperament and attention: Orienting toward and away from positive and negative signals. Journal of Personality and Social Psychology, 66, 1128-1139.

Dvorak-Bertsch, J. D., Curtin, J. J., Rubinstein, T. J., \& Newman, J. P. (2009). Psychopathic traits moderate the interaction between cognitive and affective processing. Psychophysiology, 46, 913-921

Edens, J. F., Marcus, D. K., Lilienfeld, S. O., \& Poythress, N. G., Jr. (2006). Psychopathic, not psychopath: Taxometric evidence for the dimensional structure of psychopathy. Journal of Abnormal Psychology, 115, 131-144. doi:10.1037/0021-843X.115.1.131

Edgar, J. C., Stewart, J. L., \& Miller, G. A. (2005). Digital filtering in EEG/ERP research. In T. C. Handy (Ed.), Event-related potentials: A handbook (pp. 85-113). Cambridge: MIT Press.

First, M. B., Spitzer, R. L., Gibbon, M., \& Williams, J. B. W. (2002). Structured clinical interview for DSM-IV-TR Axis I disorders, research version, non-patient edition. New York: New York State Psychiatric Institute, Biometrics Research Dept.
Flor, H., Birbaumer, N., Hermann, C., Ziegler, S., \& Patrick, C. J. (2002). Aversive Pavlovian conditioning in psychopaths: Peripheral and central correlates. Psychophysiology, 39, 505-518.

Fowles, D.C. \& Dindo, L. (2009). Temperament and psychopathy: A dual-pathway model. Current Directions in Psychological Science, $18,179-183$.

Glass, S. J., \& Newman, J. P. (2006). Recognition of facial affect in psychopathic offenders. Journal of Abnormal Psychology, 115, 815-820. doi:10.1037/0021-843X.115.4.815

Gordon, H. L., Baird, A. A., \& End, A. (2004). Functional differences among those high and low on a trait measure of psychopathy. Biological Psychiatry, 56, 516-521. doi:10.1016/j.biopsych.2004.06.030

Grillon, C., \& Baas, J. (2003). A review of the modulation of the startle reflex by affective states and its application in psychiatry. Clinical Neurophysiology, 114, 1557-1579. doi:10.1016/S1388-2457(03) 00202-5

Hajcak, G., \& Nieuwenhuis, S. (2006). Reappraisal modulates the electrocortical response to unpleasant pictures. Cognitive, Affective, \& Behavioral Neuroscience, 6, 291-297. doi:10.3758/ CABN.6.4.291

Hare, R. D. (1965). Temporal gradient of fear arousal in psychopaths. Journal of Abnormal Psychology, 70, 442-445.

Harpur, T. J., Hare, R. D., \& Hakstian, A. R. (1989). Two-factor conceptualization of psychopathy: Construct validity and assessment implications. Psychological Assessment, 1, 6-17. doi:10.1037/1040-3590.1.1.6

Hart, S. D., Cox, D. N., \& Hare, R. D. (1995). The hare psychopathy checklist: Screening version. Toronto: Multi-Health Systems.

Hiatt, K. D., Schmitt, W. A., \& Newman, J. P. (2004). Stroop tasks reveal abnormal selective attention in psychopathic offenders. Neuropsychology, 18, 50-59.

Hillyard, S. A., \& Anllo-Vento, L. (1998). Event-related brain potentials in the study of visual selective attention. Proceedings of the National Academy of Sciences, 95, 781-787.

Iacono, W. G., Carlson, S. R., Malone, S. M., \& McGue, M. (2002). P3 event-related potential amplitude and risk for disinhibitory disorders in adolescent boys. Archives of General Psychiatry, 59, 750757.

Joseph, J. E., Liu, X., Jiang, Y., Lynam, D., \& Kelly, T. H. (2009). Neural correlates of emotional reactivity in sensation seeking. Psychological Science, 20, 215-223. doi:10.1111/j.1467-9280.2009.02283.x

Jutai, J. W., \& Hare, D. (1983). Psychopathy and selective attention during performance of a complex perceptual-motor task. Psychophysiology, 20, 146-151.

Keil, A., Bradley, M. M., Hauk, O., Rockstroh, B., Elbert, T., \& Lang, P. J. (2002). Large-scale neural correlates of affective picture processing. Psychophysiology, 39, 641-649. doi:10.1017/ S0048577202394162

Kiehl, K. A. (2006). A cognitive neuroscience perspective on psychopathy: Evidence for paralimbic system dysfunction. Psychiatry Research, 142, 107-128.

Kim, M., \& Davis, M. (1993). Electrolytic lesions of the amygdala block acquisition and expression of fear-potentiated startle even with extensive training but do not prevent reacquisition. Behavioral Neuroscience, 107, 580-595. doi:10.1037/07357044.107.4.580

Krueger, R. F., Hicks, B. M., Patrick, C. J., Carlson, S. R., Iacono, W. G., \& McGue, M. (2002). Etiologic connections among substance dependence, antisocial behavior, and personality: Modeling the externalizing spectrum. Journal of Abnormal Psychology, 111, $411-424$

Lang, P. J., Bradley, M. M., \& Cuthbert, B. N. (1997). International affective picture system (IAPS): Technical manual and affective ratings (Technical Report No. A-4). Gainesville: University of Florida, Center for Research in Psychophysiology. 
Levenston, G. K., Patrick, C. J., Bradley, M. M., \& Lang, P. J. (2000). The psychopath as observer: Emotion and attention in picture processing. Journal of Abnormal Psychology, 109, 373-385.

Lorber, M. F. (2004). Psychophysiology of aggression, psychopathy, and conduct problems: A meta-analysis. Psychological Bulletin, 130, 531-552. doi:10.1037/0033-2909.130.4.531

Louth, S. M., Hare, R. D., \& Linden, W. (1998). Psychopathy and alexithymia in female offenders. Canadian Journal of Behavioral Science, 30, 91-98.

Luck, S. J. (2005). An introduction to event-related potential technique. Cambridge, MA: The MIT Press

Luck, S. J., Heinze, H. J., Mangun, G. R., \& Hillyard, S. A. (1990). Visual event-related potentials index focused attention within bilateral stimulus arrays: II. Functional dissociation of P1 and N1 components. Electroencephalography and Clinical Neurophysiology, 75, 528-542.

Lykken, D. T. (1957). A study of anxiety in the sociopathic personality. Journal of Abnormal and Social Psychology, 55, 6-10.

Malterer, M. B., Glass, S. J., \& Newman, J. P. (2008). Psychopathy and trait emotional intelligence. Personality and Individual Differences, 44, 735-745. doi:10.1016/j.paid.2007.10.007

Newman, J. P. (1998). Psychopathic behavior: An information processing perspective. In D. J. Cooke, R. D. Hare, \& A. Forth (Eds.), Psychopathy: Theory, research and implications for society (pp. 81-104). The Netherlands: Kluwer.

Newman, J. P., Curtin, J. J., Bertsch, J. D., \& Baskin-Sommers, A. (2010). Attention moderates the fearlessness of psychopathic offenders. Biological Psychiatry, 67, 66-70.

Newman, J. P., \& Kosson, D. S. (1986). Passive avoidance learning in psychopathic and nonpsychopathic offenders. Journal of Abnormal Psychology, 95, 252-256.

Olbrich, H. M., Maes, H., Gann, H., Hagenbuch, F., \& Feige, B. (2000). Auditory and visual event-related potentials in alcoholics: Abnormalities of components and brain electrical field. European Archives of Psychiatry Clinical Neuroscience, 250, 215-220.

Olofsson, J. K., Nordin, S., Sequeira, H., \& Polich, J. (2008). Affective picture processing: An integrative review of ERP findings. Biological Psychology, 77, 247-265. doi:10.1016/j. biopsycho.2007.11.006

Patrick, C. J., \& Bernat, E. M. (2009). Neurobiology of psychopathy: A two-process theory. In G. G. Berntson \& J. T. Cacioppo (Eds.), Handbook of neuroscience for the behavioral sciences (pp. 1110 1131). New York: Wiley.

Patrick, C. J., Bradley, M. M., \& Lang, P. J. (1993). Emotion in the criminal psychopath: Startle reflex modulation. Journal of Abnormal Psychology, 102, 82-92. doi:10.1037/0021-843X.102.1.82

Patrick, C. J., Hicks, B. M., Krueger, R. F., \& Lang, A. R. (2005). Relations between psychopathy facets and externalizing in a criminal offender sample. Journal of Personality Disorders, 19, 339-356. doi:10.1521/pedi.2005.19.4.339

Patterson, B. W., Williams, H. L., McLean, G. A., Smith, L. T., \& Schaffer, K. W. (1987). Alcoholism and family history of alcoholism: Effects on visual and auditory event-related potentials. Alcohol, 4, 265-274.

Pessoa, L., McKenna, M., Gutierrez, E., \& Ungerleider, L. G. (2002). Neural processing of emotional faces requires attention. Proceedings of the National Academy of Sciences, 99, 11458-11463. doi:10.1073/pnas.172403899

Pessoa, L., Padmala, S., \& Morland, T. (2005). Fate of unattended fearful faces in the amygdala is determined by both attentional resources and cognitive modulation. NeuroImage, 28, 249-255. doi:10.1016/j.neuroimage. 2005.05 .048

Reardon, M. L., Lang, A. R., \& Patrick, C. J. (2002). Antisociality and alcohol problems: An evaluation of subtypes, drinking motives, and family history in incarcerated men. Alcoholism: Clinical and Experimental Research, 26, 1188-1197.
Ross, S. R., Benning, S. D., Patrick, C. J., Thompson, A., \& Thurston, A. (2009). Factors of the Psychopathic Personality Inventory: Criterion-related validity and relationship to the BIS/BAS and five-factor models of personality. Assessment, 16, 71-87. doi: $10.1177 / 1073191108322207$

Rossion, B., \& Jacques, C. (2008). Does physical interstimulus variance account for early electrophysiological face sensitive responses in the human brain? Ten lessons on the N170. NeuroImage, 39, 19591979

Sabatinelli, D., Bradley, M. M., Fitzsimmons, J. R., \& Lang, P. J. (2005). Parallel amygdala and inferotemporal activation reflect emotional intensity and fear relevance. NeuroImage, 24, 1265-1270.

Sadeh, N., \& Verona, E. (2008). Psychopathic personality traits associated with abnormal selective attention and impaired cognitive control. Neuropsychology, 22, 669-680. doi:10.1037/a0012692

Schupp, H. T., Cuthbert, B. N., Bradley, M. M., Cacioppo, J. T., Ito, T., \& Lang, P. J. (2000). Affective picture processing: The late positive potential is modulated by motivational relevance. Psychophysiology, 37, 257-261.

Schupp, H. T., Junghöfer, M., Weike, A. I., \& Hamm, A. O. (2004). The selective processing of briefly presented affective pictures: An ERP analysis. Psychophysiology, 41, 441-449. doi:10.1111/ j.1469-8986.2004.00174.x

Sellbom, M., \& Verona, E. (2007). Neuropsychological correlations of psychopathic traits in a non-incarcerated sample. Journal of Research in Personality, 41, 276-294.

Smith, S. S., \& Newman, J. P. (1990). Alcohol and drug abuse in psychopathic and nonpsychopathic criminal offenders. Journal of Abnormal Psychology, 99, 430-439.

Sprague, J., \& Verona, E. (2010). Emotional conditions disrupt behavioral control among individuals with dysregulated personality traits. Journal of Abnormal Psychology, 119, 409-419. doi:10.1037/a0019194

Sutton, S. K., Vitale, J. E., \& Newman, J. P. (2002). Emotion among females with psychopathy during picture perception. Journal of Abnormal Psychology, 111, 610-619.

Vaidyanathan, U., Hall, J. R., Patrick, C. J., \& Bernat, E. M. (2011). Clarifying the role of defensive reactivity deficits in psychopathy and antisocial personality using startle reflex methodology. Journal of Abnormal Psychology, 120, 253-258. doi:10.1037/a0021224

Venables, N. C., Patrick, C. J., Hall, J. R., \& Bernat, E. M. (2011). Clarifying relations between dispositional aggression and brain potential response: Overlapping and distinct contributions of impulsivity and stress reactivity. Biological Psychology, 86, 279288. doi:10.1016/j.biopsycho.2010.12.009

Verona, E., Patrick, C. J., \& Joiner, T. E. (2001). Psychopathy, antisocial personality, and suicide risk. Journal of Abnormal Psychology, 110, 462-470. doi:10.1037/0021-843X.110.3.462

Verona, E., Sprague, J., \& Sadeh, N. (in press). Inhibitory control and negative emotional processing in psychopathy and antisocial personality disorder. Journal of Abnormal Psychology.

Vitale, J. E., Brinkley, C. A., Hiatt, K. D., \& Newman, J. P. (2007). Abnormal selective attention in psychopathic female offenders. Neuropsychology, 21, 301-312. doi:10.1037/0894-4105.21.3.301

Vitale, J. E., Smith, S. S., Brinkley, C. A., \& Newman, J. P. (2002). The reliability and validity of the Psychopathy Checklist-Revised in a sample of female offenders. Criminal Justice and Behavior, 29, 202-231. doi:10.1177/0093854802029002005

Wallace, J. F., \& Newman, J. P. (1997). Neuroticism and the attentional mediation of dysregulatory psychopathology. Cognitive Therapy and Research, 21, 135-156.

Wechsler, D. (1997). Wechsler Adult Intelligence Scale -WAIS III (3rd ed.). San Antonio: Harcourt Assessment.

Zeier, J. D., Maxwell, J. S., \& Newman, J. P. (2009). Attention moderates the processing of inhibitory information in primary psychopathy. Journal of Abnormal Psychology, 118, 554-563. 